\title{
PREVALENCE OF NECK PAIN AND LAPTOP USING BEHAVIOUR AMONG POST GRADUATE STUDENTS
}

\section{Monika Bodwal ${ }^{1}$, Priyanka Rana ${ }^{*}$, Shabnam Joshi ${ }^{3}$.}

${ }^{1}$ MPT (Musculoskeletal Disorders), Department of Physiotherapy, Guru Jambheshwar University of Science and Technology, Hisar, Haryana, India.

${ }^{*}$ MPT (Musculoskeletal Disorders), Department of Physiotherapy, Guru Jambheshwar University of Science and Technology, Hisar, Haryana, India.

${ }^{3}$ Assistant Professor, MPT (Musculoskeletal), Department of Physiotherapy, Guru Jambheshwar University of Science and Technology, Hisar, Haryana, India.

\section{ABSTRACT}

Background: Peoples who use laptops are at greater risk for neck pain complaints. The incidence and prevalence of neck pain is increased with the development of information technology and the move toward service sector oriented employment and which is further influenced by an increase in sedentary work as well as occupational and recreational computer use. The prevalence of neck pain due to laptop use is surveyed among post-graduation students as their computing hours are higher because these students are further into their education and are completing masters requiring research.

Purpose of study: To survey (a) The prevalence of neck pain due to laptop use among the post graduate students (b) To assess the laptop using behavior by using student laptop use and neck pain risk questionnaire (SLUNPRQ) developed by Gray, D.( 2011).

Materials and Methods: A Qualitative survey study with questionnaire was conducted at Guru Jambheshawar University of Science and Technology, Hisar. 150 post graduate students were taken as per selection criteria which included both male and female between the age group of 21 to 25 years. Using convenience sampling, the Student Laptop Use and Neck Pain Risk Questionnaire with informed consent was distributed among 150 post graduate students. The prevalence of neck pain due to laptop use and the laptop using behavior by using student laptop use were taken as outcome measurement parameters. Qualitative Content Analysis has been used for the analysis of the data.

Results: It was observed that long time use of laptop was ergonomically inappropriate. The prevalence of neck pain and other musculoskeletal problems was found higher in most of the students because of the extended use and adopting improper posture while using laptop. Poor adaptation of posture was mainly because of unawareness about laptop ergonomics.

Conclusion: The present study concluded that there is higher prevalence of neck pain in post graduate students due to lack of awareness about the proper posture for laptop use among them.

KEY WORDS: Neck Pain, Laptop Ergonomics, Laptop Related Injury, Laptop Associated Musculoskeletal Disorders.

Address for correspondence: Dr. Priyanka Rana, MPT (Musculoskeletal Disorders), Guru Jambheshwar University of Science and Technology, Hisar, Haryana, India.

Contact number : 09811675834 E-Mail : priyankarana2535@yahoo.com

\begin{tabular}{|l|l|}
\hline \multicolumn{3}{|c|}{ Access this Article online } \\
\hline Quick Response code & International Journal of Physiotherapy and Research \\
ISSN 2321- 1822
\end{tabular}




\section{INTRODUCTION}

Musculoskeletal pain has become a considerable issue worldwide, and encompasses a wide range of musculoskeletal tissue injuries, some of which are work related. These kind of disorders affect many areas of the body such as the neck, upper extremities or back [1]. Neck pain may arise from any of the innervated structures in the neck, such as intervertebral discs, muscles, ligaments, zygapophyseal joints, dura or nerve roots [2]. However in the majority of cases, the patho-physiological mechanisms underlying neck pain are unclear.

Nowadays, laptops are becoming so useful, fast and powerful that they are frequently replacing desktop computers and bring many benefits to students. It was reported by Shears (1995) and McDonald (1995) that laptops provide flexibility in the learning process and that students appear to enjoy using them. B Laptop users frequently assume inconvenient postures while using laptops. Some of these postures are lying on the floor, using desks that are not designed for computers, and placing the laptop on one's lap. This leads to uncomfortable or unhealthy postures for the laptop users that may lead to injury or discomfort [3].

Over the past decade, the interest among the student population in using the laptop as an institutional tool has increased [4]. University campus and student population are also affected by the advantageous contributions of technologies such as laptops and computers. In the last decade it was observed that the use of laptops being increasingly used by students, it was also noticed that $80 \%$ of British students own a laptop while $40 \%$ spending $3-4$ hours a day online [5-6].

It may be noted, that the laptop was not designed for long or constant use [5]. Undoubtedly, this has resulted in a sequence of illnesses affecting different parts of the body. These include pain in the neck, upper back, hands and wrists, numbness, swellings, and tingling sensation [7]. It was also observed that Migraine, damages to the spine and nerve related ailments are increasing among the student population [8]. With the growing use of laptops by students in school and colleges, it is clear that university student population are potentially at a higher risk for developing neck and upper limb pain, so it is needed that musculoskeletal disorders in relation to laptop use are well understood to allow for appropriate precautions to be taken. The higher reported computing hours are expected among the post-graduation students because these students are further into their education and are completing masters which requires report writing and research. So the present study is aimed at determining the prevalence of neck pain and laptop using behavior among university Post Graduate student population.

\section{MATERIALS AND METHODS}

Research Design : A Qualitative study design with questionnaire survey was used.

Sampling: A sample of 150 post graduate students were selected based on inclusion criteria by 'convenience sampling' as it was not possible to approach all the student population in Guru jambheshwar University.

Instrumentation: The student laptop use and neck pain risk questionnaire (SLUNPRQ) developed by Gray, D. (2011)[15] were used to study the postural discomfort while using laptop was recorded.

\section{Selection criteria}

Inclusion Criteria: Students pursuing postgraduation in University, Students using laptop for course work, age group 21 to 25 years.

Exclusion Criteria: Students who were not belonging to University, Students who were not using laptop, Uncooperative students.

Procedure: Subjects were contacted personally in their respective educational institution for data collection after obtaining permission from the relevant Head of the department. After getting consent of subjects congenial rapport was established to make them comfortable. They were provided the basic instructions for filling the questionnaire. The students were instructed of the voluntary nature of the study via the informed consent paragraph at the beginning of the survey.All participants completed the questionnaire and returned it.

Data analysis: The data was analyzed using the SPSS software (version 16.0). Percentage and 
frequency were calculated and represented by using bar graph.

Demographic distribution of study subjects was determined. Prevalence of neck pain in study subjects was also determined.

\section{RESULTS}

Table 1: Percentage of students having Pain or discomfort in neck or upper extremities after using laptop.

\begin{tabular}{|c|c|c|}
\hline PD & Y & N \\
\hline$\%$ & 78.7 & 21.3 \\
\hline
\end{tabular}

Table 2: Duration of pain or discomfort continued after laptop use.

\begin{tabular}{|c|c|c|c|c|c|}
\hline DOS & $<30 \mathrm{~min}$ & $30-60 \mathrm{~min}$ & $1-6$ hours & $6-24$ hours & 1 day \\
\hline$\%$ & 50 & 24 & 6 & 0 & 2 \\
\hline
\end{tabular}

Table 3: Affected areas of body after the use of laptop.

\begin{tabular}{|c|c|c|c|c|c|}
\hline AA & Neck & Shoulder & Elbow & Forearm & W/H/F \\
\hline$\%$ & 69.3 & 22 & 6.7 & 7.3 & 27.3 \\
\hline
\end{tabular}

Table 4: Number of hours per week of laptop use by students for recreational, academic and work related purposes.

\begin{tabular}{|c|c|c|c|c|}
\hline Time/week & $<6$ hours & $\mathbf{6 - 1 2}$ hours & $\mathbf{1 2 - 2 0}$ hours & $>\mathbf{2 0}$ hours \\
\hline R \% & 60 & 32.7 & 2.7 & 4 \\
\hline A \% & 58.7 & 30 & 7.3 & 4 \\
\hline WR \% & 66.7 & 24.7 & 6 & 2.7 \\
\hline
\end{tabular}

Table 5: Posture adopted by students while using laptop for recreational, academic and work related purposes.

\begin{tabular}{|c|c|c|c|c|c|}
\hline LUP & NN & NF & SF & SB & LOS \\
\hline R \% & 4 & 2 & 9.3 & 45.3 & 39.3 \\
\hline A \% & 15.3 & 20 & 52 & 10 & 2.7 \\
\hline WR \% & 18 & 23.3 & 38.7 & 17.3 & 2.7 \\
\hline
\end{tabular}

Table 6: Duration of breaks taken while using laptop for recreational, academic, and work related purposes.

\begin{tabular}{|c|c|c|c|}
\hline BD & $<\mathbf{1 5} \mathbf{~ m i n}$ & $\mathbf{1 5 - 4 5} \mathbf{~ m i n}$ & $>\mathbf{4 5} \mathbf{~ m i n}$ \\
\hline $\mathbf{R} \%$ & 56 & 16 & 4 \\
\hline A \% & 54 & 30.7 & 2.7 \\
\hline WR \% & 54.7 & 28.7 & 6.7 \\
\hline
\end{tabular}

Table 7: Number of breaks taken while using laptop for recreational, academic and work related purposes.

\begin{tabular}{|c|c|c|c|c|}
\hline NOB & 0 break & 1-2 break & 3-4 break & 5-6 break \\
\hline R \% & 34.7 & 48.7 & 14 & 1.3 \\
\hline A \% & 20.7 & 56.7 & 18.7 & 2.7 \\
\hline WR \% & 19.3 & 56.7 & 21.3 & 1.3 \\
\hline
\end{tabular}

The students suffered frequently from various musculoskeletal health problems like pain or discomfort in neck (69.3\%), shoulder (22\%), wrist, hand and fingers (27.3\%) whereas very few students experienced pain in forearm (7.3) and elbow (6.7\%) after laptop's usage.Some of students used external mouse (25.3\%) and external monitor (10\%) only for academic purposes. It was also observed that $45.3 \%$ of students adopted a posture of slouching backward while $39.3 \%$ of the students adopted a posture of lying on stomachwhile performing recreational activities. For academic purposes, result showed that $52 \%$ of students adopt slouching forward posture. For work related purposes, result showed that $38.7 \%$ of students adopt slouching forward posture and $23.3 \%$ of students adopt neck flexion posture.Students preferred to take breaks for academic (78\%) and work related (81.3\%) purposes.

The focus of this study was on neck pain due to the use of laptop and there was a question-concerning other reasons contributing to neck pain in the questionnaire. So, some of the students reported neck pain due to wrong posture of sitting for long hours, sleeping in wrong position, longer duration of studying, during travelling, constantly seeing on black board, use of high pillow and excessive use of mobile phone. Very few students also reported irritation in eyes, pain in upper part of vertebra, pain in scapular region, headache, backache and mental stress increases after the use of laptop.

\section{DISCUSSION}

Jacobs et al in 2009 studied that $75.8 \%$ of student population use laptops in their educational institutions [9]. According to a study by Smith et al it was noticed that there is increase in laptop ownership from $66 \%$ in 2006 to $88 \%$ in the year 2009 [12]. With increasing tendency of laptop use among students it is clear that research on the prevalence of developing MSDs due to laptop use is essential among this demographic. It is very evident from the results that maximum pain or discomfort is experienced in neck (69.3\%). According to a study by Kumari and Pandey (2010) it was also observed that similar type of result with $80 \%$ of participants were facing symptoms in neck, back, wrists, forearms, elbows followed by eye strain (42\%) during the usage of computer. Kumari and Pandey (2010) also found that prolonged sitting in awkward or poor postures were the common causes of these symptoms [9].

Due to not having the ergonomics awareness, 
student population adopts poor posture while working on laptop which leads to discomfort and pain. In the present study, $45.3 \%$ of students adopted a posture of slouching backward and $39.3 \%$ of the students adopted a posture of lying on stomach while performing recreational activities. For academic and work related purposes, majority of students adopted slouching forward posture. A study by Moffet et al. (2002) also supported the result showing impact of two work situations (Laptop and desktop) on muscle activity and neck postures of individuals. They observed that during the use of laptop individuals bend their head forward, had more back trunk inclination and wrist extension, resulting in more symptoms in back, wrist and neck. It was found that the setup of workstation influenced the physical exposure inconsistent while working on laptop [13]. Straker et al. (1997a) also reported that users of laptop tried to assume posture that would compromise their typing posture by increased neck, shoulder and elbow flexion. They adopt this posture in order to see a lower screen and reach a higher keyboard [10]. Harbison and Forrester (1995) also found that laptop users required increased forward head inclination because of lack of adjustability of laptop screen [16]. A study done by Ariens et al. also found a positive relation between neck flexion and neck pain, suggesting an increased risk of neck pain for those who spent a high percentage of the working time with the neck at a minimum of 20 degree of flexion [14].

From the results, it was also found that majority of studentsdo not prefer to use computer accessories which might result in more pain and discomfort. Kumari and Pandey (2010) also support the use of various computer accessories like- adjustable keyboard tray, foot rest, Best-fit computer mouse design, task lighting and docking station which can help in preventing the health related symptoms [9].

It was observed in the present study that majority of student population take breaks during extended periods of using laptop. Results showed that $56 \%$ of students take break for less than 15 minutes for recreational purposes, 54\% for academic and $54.7 \%$ of students for work related purposes. The overall result shows that majority of students take break for less than 15 minutes during working on laptop. Menendez et al in 2008 also supported results that taking breaks for less than 15 minutes was negatively associated with any symptoms. This brings attention to the idea that smaller breaks may be as beneficial or, possibly, more beneficial than larger breaks when computing [11].

\section{CONCLUSION}

The present study concluded that there is high prevalence of neck pain (69.3\%) due to laptop use among the university post graduate students. The discomfort or pain lasted for at least less than half an hour after laptop use. The students adopted poor postures such as slouching forward, andlying on stomach during working on laptop.

\section{ABBREVIATION}

PD - Pain or Discomfort, $\mathbf{Y}$ - Yes, N - No, NOBNumber of break, R-Recreational, A- Academic, WR- Work related, BD- Break duration, BDCBreak during computing, EM- External monitor, LUP- Laptop use posture, NN- Neck neutral, NFNeck flexion, SF- Slouching forward, SB-Slouching backward, LOS- Laying on stomach, AA Affected areas, W/H/F - Wrist, Hand, Fingers, DOS - Duration of symptoms.

\section{Conflicts of interest: None}

\section{REFERENCES}

[1]. Green, B. N. A literature review of neck pain associated with computer use: public health implications. The Journal of the Canadian Chiropractic Association 2008;52(3):161.

[2]. Bogduk, N., Neck pain: an update. Aust Fam Physician 1998;17:75-80.

[3]. Rafael Moras, Ph.D. A survey of ergonomic issues associated with a university laptop program. St. Mary s University, San Antonio, TX, USA, 2007;1(2).

[4]. Gulek, J. C. and Demirtas, H. Learning with technology: The impact of laptop use on student achievement. Journal of Technology, Learning, and Assessment, 2005;3(2).

[5]. Harris, C. and Straker, L. Survey of Physical Ergonomics Issues Associated with School Children s Use of Laptop Computers. International Journal of Industrial Ergonomics, 2000;26:337-346.

[6]. Thrasher, M. and Chesky, K. Medical Problems of Clarinetists. Results from the UNTMusician Health Survey. Texas Music Education Research 1998; Last Accessed. 19 $9^{\text {th }}$ Dec 2011 at http://www.tmea.org/ 080_College/Research/thr1998.pdf. 
[7]. Kumari, G. and Pandey, K.M. Studies on health problems of software people: A case study of Faculty of GCE and GIMT Gurgaon, India. International Journal of Innovation, Management and Techonology 2010;1(1):388-397.

[8]. Mekhora, K. and Liston, C. The effect of ergonomic intervention on discomfort in computer users with tension neck syndrome. International. Journal of Industrial Ergonomics, 2000;26(3):367-379.

[9]. Jacobs, K. University students' notebook computer use. Applied Ergonomics 2009;40(3):404-409.

[10]. STRAKER, Leon, JONES, Kerry J. and MILLER, Jenni (1997). A comparison of the postures assumed when using laptop computers and desktop computers. Applied ergonomics, 1997;28(4):263-268.

[11]. Menendez, C., Amick, B., Chang, C., Dennerlein, J., Harrist, R., Jenkins, M., . . . Katz, J. Computer use patterns associated with upper extremity musculoskeletal symptoms. Journal of Occupational Rehabilitation 2008;18(2):166-174.

[12]. Smith, S. D., Salaway, G., \& Caruso, J. B. The ECAR study of undergraduate students and information technology, 2009;6. Retrieved from http:// w w w. ed u c a u s e. ed u/Resources / TheECARStudyofUndergraduateStu/187215.
[13]. Moffet, H., Hagberg, M., Hansson-Risberg, E. and Karlqvist, L. (2002) Influence of laptop computer design and working position on physical exposure variables. Clinical Biomechanics 2002;17:368-375. http://dx.doi.org/10.1016/S0021-9290(02)00062-3.

[14]. Ariëns, G., Bongers, P., Douwes, M., Miedema, M., Hoogendoorn, W., Van der Wal, G. Van Mechelen, W. Are neck flexion, neck rotation, and sitting at work risk factors for neck pain? Results of a prospective cohort study. Occupational and environmental medicine, 2001;58(3):200.

[15]. Development of Instruments to Assess Physiological and Physical Neck Pain Risk factors by Diana Gray University of Ontario Institute of Technology, Oshawa July, 2011.

[16]. Harbison ,S. and Forrester, C. Ergonomics of notebook computers. Journal of Occupational Health and Safety - Australia and New Zealand. 1995;11:481-487.

How to cite this article:

Monika, Priyanka Rana, Shabnam Joshi. PREVALENCE OF NECK PAIN AND LAPTOP USING BEHAVIOUR AMONG POST GRADUATE STUDENTS. Int J Physiother Res 2017;5(4):2271-2275. DOI: 10.16965/ijpr.2017.185 